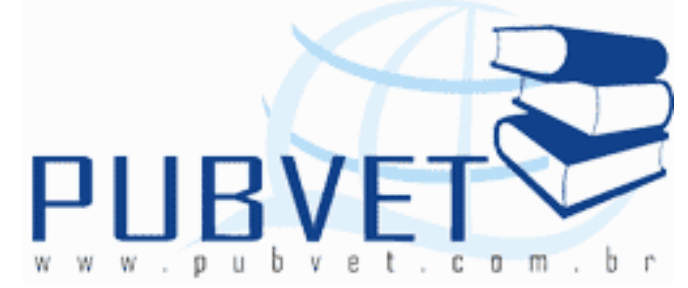

PUBVET, Publicações em Medicina Veterinária e Zootecnia.

\title{
Avaliação termográfica da musculatura pélvica de equinos da modalidade esportiva de três tambores
}

Luciana Cristina Carrenho Sala ${ }^{1}$, Mariana Carril Elui ${ }^{2}$, Marina Canesin Jardim ${ }^{3}$

${ }^{1}$ Docente de Clínica Médica de Grandes Animais, Centro Universitário Barão de Mauá, Ribeirão Preto - SP, Brasil. e-mail: lucarrenho@gmail.com.

${ }^{2}$ Médica veterinária autônoma de equinos, Ribeirão Preto - SP, Brasil.

${ }^{3}$ Médica veterinária residente do Centro Universitário Barão de Mauá, Ribeirão Preto-SP, Brasil.

\section{Resumo}

O objetivo do presente estudo foi determinar a influência do exercício no aumento da temperatura muscular pélvica de equinos, que treinam na modalidade de três tambores. Foi realizada a análise termográfica da musculatura de quatro equinos da raça Quarto-de-Milha, com peso médio de $480 \mathrm{~kg}$, e idade entre 6 e 8 anos. Foram obtidas imagens termográficas de ambos os lados dos músculos semimembranoso (SM), semitendinoso (ST) e glúteo superficial (GS), captadas em três diferentes momentos: M0: antes do treinamento, M1: 5 minutos após o treinamento e M2: 2 horas após término do treinamento. Os resultados observados demonstraram que a região muscular pélvica que demonstrou maior incremento da temperatura foi o músculo SM. Foram também verificados aumentos estatisticamente significativos $(p<0,05)$ de temperatura na musculatura pélvica logo após o 
exercício de três tambores (M1), no entanto, com retorno à temperatura basal após 2 horas do final do exercício (M2).

Palavras-chave: condicionamento, musculatura, semimembranoso, semitendinoso, glúteo superficial.

\section{Pelvic musculature thermography evaluation of barrel racing horses.}

\section{Abstract}

The aim of this study was to determine the increase in temperature due to exercise in hind limb musculature of barrel racing horses. Infrared thermography analyses were done on 4 (four) Quarter horses, of $480 \mathrm{~kg}$ average weight, from 6 to 8 years old. Thermographic images of the left and right side of semimembranous (SM), semitendineous (ST) and superficial gluteous (SG) muscles were obtained and each one was measured in three different moments: M0: before exercise, M1: 5 minutes after exercise and M2: two hours after. The highest increment in temperature was observed in ST. It was also verified temperature increase in the pelvic musculature in $M 1$ in a significant way $(p<0,05)$, although returning to basal temperature 2 hours after the end of exercise (M2).

Keywords: conditioning, musculature, semimembranous, semitendineous, superficial gluteous.

\section{INTRODUÇÃO}

O equino atleta moderno desempenha diversas atividades esportivas que passaram a exigir um desempenho cada vez maior em razão da competitividade (RESENDE, 2005). O esforço excessivo acaba acarretando diversos problemas, sendo que localizar a sede exata de uma lesão nem sempre é uma tarefa fácil, principalmente quando está relacionada a problemas musculares. A dor nem sempre é decorrente da lesão primária observada, e, o grande tamanho dos músculos do equino não facilitam a precisão do diagnóstico (BOFFI et al., 2006). 
Segundo Yanmaz et al.(2007), as câmeras infravermelhas surgiram em 1950 durante a Segunda Guerra Mundial como uma forma de monitorar o exército inimigo, e posteriormente começaram a ser usadas na medicina. $\mathrm{Na}$ Medicina veterinária foi introduzida em 1966, e desde então seu uso vem sendo cada dia mais estudado. A termografia é um método não-invasivo que auxilia no diagnóstico de lesões musculares, tornando-se um recurso cada vez mais utilizado na medicina esportiva equina (SHAMAA; GOHAR, 2002; TEODORA et al., 2007). Dessa maneira, o exame termográfico torna-se importante tanto para o reconhecimento precoce das lesões quanto para a abordagem do condicionamento dos animais de uma das modalidades de maior expressão, como a prova de três tambores.

O objetivo desse estudo foi determinar a influência do exercício físico realizado na prova de Três Tambores nas alterações de temperatura dos músculos semitendinoso (ST), semimembranoso (SM) e glúteo superficial (GS), visando o conhecimento do grupo muscular mais exigido durante essa modalidade de esporte, correlacionando ao condicionamento de equinos atletas.

\section{MATERIAL E MÉTODOS}

Foram utilizados 4 equinos ( 3 machos e 1 fêmea), da raça Quarto-deMilha, com peso médio de $480 \mathrm{Kg}(470-510 \mathrm{Kg})$. Visando a homogeneidade foram selecionados animais entre 6 e 8 anos de idade, que possuíam em média 2 anos de treinamento na modalidade de três tambores. Os animais ficavam em cocheira de tamanho $4 \mathrm{~m} \times 4 \mathrm{~m}$ e em piquete individual ( $25 \mathrm{~m} \times$ $25 \mathrm{~m}$ ) por aproximadamente 3 horas. A alimentação consistia em fornecimento de feno de Coast-cross e água ad libitum e 4,5 $\mathrm{Kg}$ de ração, divididos em três porções diárias (Purina ${ }^{\circledR}$ de $3.000 \mathrm{Kcal} ; 15 \%$ de proteína Bruta e $6 \%$ de extrato etério).

No dia anterior ao exame termográfico os animais eram lavados com água corrente e mantidos em cocheira, sem a incidência de luz solar até o momento do exame. Uma vez que o ato de escovar ou tocar o local de 
interesse produz um incremento na temperatura local e o mesmo também precisa estar livre de sujidades (partículas de poeira, areia, serragem) para que não interfiram na imagem termográfica. Os equinos eram escovados 30 minutos antes da primeira captura de imagem, e só depois selados.

É importante ressaltar que houve padronização de todo o equipamento utilizado como selas, mantas, caneleiras e cloches. Além disso, os animais foram montados pelo mesmo cavaleiro, buscando assim diminuir qualquer interferência no resultado com relação ao peso sobre o animal, sendo assim, o peso total do conjunto (indivíduo e equipamentos) correspondeu a $89 \mathrm{Kg}$.

Utilizou-se 0 termógrafo da marca FLUKE $^{\circledR}$, modelo Ti9, com sensibilidade de $0,1^{\circ} \mathrm{C}$ e precisão de $\pm 5^{\circ} \mathrm{C}$ e configurado com emissividade $\varepsilon$ $=0.98$. Para mensuração da temperatura ambiente e da umidade relativa do ar durante a coleta de dados foi utilizada uma Estação Metereológica Avançada (Oregon ${ }^{\circledR}$ modelo WMR100).

Os animais realizavam o percurso da prova em uma pista que apresentava a medida de 90 metros de comprimento, 40 metros de largura, preenchida por aproximadamente $25 \mathrm{~cm}$ de areia. Para a avaliação termográfica foi estipulado um protocolo de aquecimento prévio dos animais, consistindo na padronização dos seguintes passos sucessivamente: caminhar durante 3 minutos em linha reta no piso duro; caminhar durante 3 minutos ao redor da pista de treinamento; trotar durante 4 minutos ao redor da pista, sendo 2 minutos em cada sentido; trotar durante 6 minutos em círculo pequeno (12 m diâmetro), sendo 3 minutos para cada lado; galopar durante 6 minutos em círculo pequeno, sendo 3 minutos para cada lado;

Logo após era realizado o percurso da prova percorrendo aproximadamente 128 metros, no qual estavam dispostos os tambores de forma triangular. Após a prova o animal era então encaminhado de volta para as cocheiras, durante 5 minutos.

Para minimizar efeitos adversos durante a coleta de dados, foi seguida a padronização de realização de exames termográficos em equinos proposta por Basile et al. (2010). Todas as imagens foram realizadas no período da manhã 
(entre às 8 e 10 horas) com umidade do ar média de $44,5 \%$ e temperatura ambiente média de $25,8^{\circ} \mathrm{C}$ variando de $24,2^{\circ}$ a $26,3^{\circ} \mathrm{C}$, buscando assim evitar que variações na temperatura ambiente interferissem nos resultados, com proteção à interferência do vento e realizadas no mesmo local.

A captura das imagens termográficas foi realizada em 3 diferentes momentos: (M0) antes do treinamento, (M1) 5 minutos após o treinamento, (M2) 2 horas após o treinamento. Ao voltarem do percurso da prova a sela era retirada sem que a região de interesse (garupa) sofresse qualquer contato, e em seguida ( 5 minutos após a passada) realizado a captura da segunda imagem (M1). No momento seguinte os animais eram lavados com água corrente, secados à sombra para evitar que a incidência de raios solares interferisse nos resultados, permanecendo na cocheira por 1 hora e 30 minutos. Em seguida eles eram retirados da mesma, novamente escovados e após 30 minutos da escovação realizava-se a última captura de imagem (M2).

Nas duas semanas que antecederam a realização do experimento nenhum medicamento tópico ou sistêmico foi aplicado.

As imagens foram realizadas no modo automático e a paleta de cores usada para os 4 animais foi a mesma (vermelho-azul), evitando assim que pudessem existir representações diferentes e consequentemente erros de interpretação das imagens. Estas foram capturadas sempre no mesmo local coberto e protegido de corrente de ar, com o foco na inserção do rabo e à dois metros de distância dos outros animais envolvidos. Para possibilitar a melhor visualização do músculo semimembranoso foi realizada também a imagem elevando a cauda do animal

A análise foi realizada com o programa Fluke ${ }^{\circledR}$ Smart View 3.1, com formatos distintos das imagens adquiridas: o primeiro utilizando o contorno anatômico ao redor do músculo GS, e outro com formato de retângulo, para as musculaturas do SM e ST (Figura 1). 


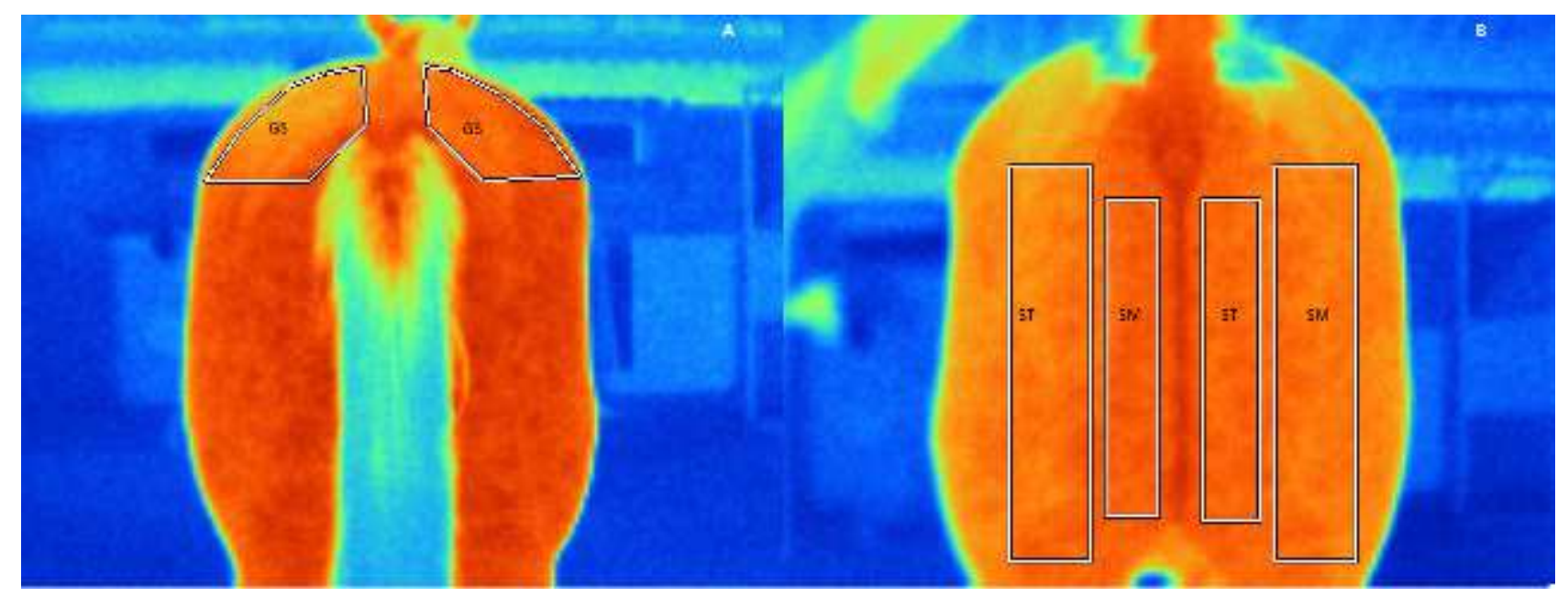

Figura 1- Imagens termográficas da musculatura pélvica de um equino demonstrando o contorno da musculatura pélvica analisada, utilizando a paleta de cores vermelho-azul.A- contorno anatômico ao redor do músculo glúteo superficial (GS). B- contorno retangular ao redor dos músculos semitendinoso (ST) e semimembranoso (SM)

Os dados obtidos na termografia foram submetidos ao teste de Tukey para comparações múltiplas das médias, considerando-se significativos valores com $p<0,05$. As análises estatísticas foram efetuadas empregando-se um programa computacional ${ }^{a}$.

\section{RESULTADOS E DISCUSSÃO}

A análise dos dados foi realizada considerando-se a média dos 4 equinos em cada musculatura (Tabela 1 ).

Observando-se o Desvio Padrão da média dos quatro animais, observouse variação de $0,6^{\circ} \mathrm{C}$ no músculo STD (Semitendinoso direito) à $1,5^{\circ} \mathrm{C}$ no músculo SME (Semimembranoso esquerdo). Segundo Jodkowska et al. (2011), na avaliação de 35 cavalos de prova de salto, o desvio padrão das temperaturas da mesma região de musculatura pélvica variou entre 1,3 e $4,4^{\circ} \mathrm{C}$. Verificou-se também que no $\mathrm{M} 1$ o Desvio Padrão da média dos quatro animais teve variação entre $0,5^{\circ}$ e $1,4^{\circ} \mathrm{C}$, na musculatura do lado esquerdo

\footnotetext{
${ }^{a}$ GraphPad Instat 3, GraphPad Software Inc., San Diego, CA, EUA.
} 

equinos da modalidade esportiva de três tambores. PUBVET, Londrina, V. 6, N. 29, Ed. 216, Art. 1437, 2012.

acreditando-se então que a variação máxima de temperatura que esses grupos musculares possam sofrer após um esforço físico está dentro dessa faixa de temperatura sem indicar uma lesão na musculatura.

Tabela 1 - Temperaturas $\left({ }^{\circ} \mathrm{C}\right)$ representadas pela média \pm desvio-padrão (DP) das diferentes regiões anatômicas cutâneas submetidas à termografia antes do exercício (M0), 5 minutos após o exercício (M1) e 2 horas após o exercício (M2).

\begin{tabular}{c|c|c|c|c|c|c}
\hline \multirow{2}{*}{ Músculo } & \multicolumn{2}{|c|}{ M0 } & \multicolumn{2}{c|}{ M1 } & \multicolumn{2}{c}{ M2 } \\
\cline { 2 - 7 } & & & & & \\
& E & D & E & D & E & D \\
\hline ST & $33,4^{\mathrm{a}}( \pm 1,2)$ & $33,7^{\mathrm{a}}( \pm 1,2)$ & $36,1^{\mathrm{b}}( \pm 0,7)$ & $36,2^{\mathrm{b}}( \pm 0,6)$ & $34,0^{\mathrm{a}}( \pm 1,3)$ & $34,1^{\mathrm{a}}( \pm 1,1)$ \\
\hline SM & $33,6^{\mathrm{a}}( \pm 1,5)$ & $33,7^{\mathrm{a}}( \pm 1,4)$ & $36,8^{\mathrm{b}}( \pm 0,5)$ & $36,8^{\mathrm{b}}( \pm 0,7)$ & $34,2^{\mathrm{a}}( \pm 1,0)$ & $34,4^{\mathrm{a}}( \pm 1,0)$ \\
\hline GS & $31,8^{\mathrm{a}}( \pm 1,1)$ & $31,7^{\mathrm{a}}( \pm 1,2)$ & $34,3^{\mathrm{b}}( \pm 1,4)$ & $34,6^{\mathrm{b}}( \pm 1,0)$ & $32,9^{\mathrm{a}}( \pm 0,8)$ & $32,8^{\mathrm{a}}( \pm 1,0)$ \\
\hline
\end{tabular}

Médias seguidas de letras distintas diferem significativamente entre si pelo teste de Tukey $(P<0,05)$. ST (semitendinoso); SM (semimembranoso); GS (glúteo superficial); E (esquerdo); D (direito).

Na avaliação termográfica, segundo Teodora et al. (2007), o aumento de temperatura maior do que $1^{\circ} \mathrm{C}$ em duas regiões anatomicamente simétricas pode ser considerado anormal, sendo que a Gráfico 1 demonstra uma mínima variação da média das temperaturas em cada músculo, comparando-se o lado esquerdo e direito, demonstrando que as regiões não diferiram estatisticamente $(p>0.05)$, dentro dos diferentes momentos (M0; M1; M2). Tal observação pode ter ocorrido decorrente dos quatro animais já estarem sendo treinados há pelo menos dois anos e sempre pelo mesmo treinador, podendo-se aferir o bom condicionamento dessas musculaturas com o auxílio do aparelho termográfico. 


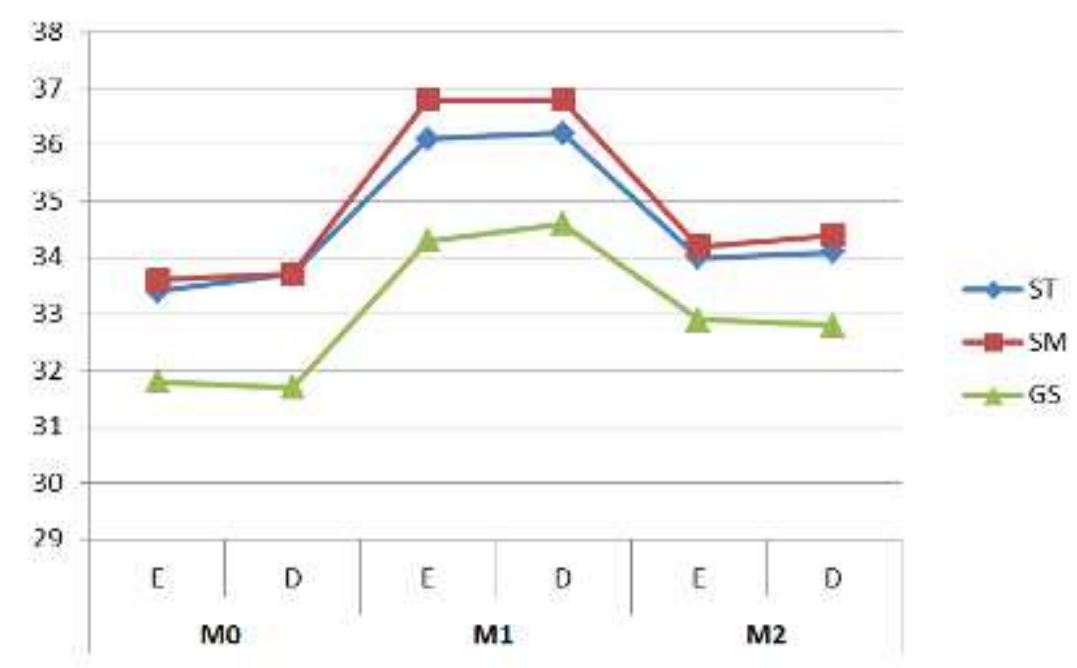

Gráfico 1 - Comparação da temperatura $\left({ }^{\circ} \mathrm{C}\right)$ do lado esquerdo e direito dos músculos semitendinoso (ST), semimebranoso (SM) e glúteo superficial (GS), nos momentos M0: antes do exercício; M1: 5 minutos após o exercício e M2: 2 horas após o exercício.

Buscando verificar o esforço realizado pelas musculaturas, foi realizada a comparação das mesmas nos diferentes momentos, entre M0 e M1 e M0 e M2. No que se refere à comparação do $M 0$ com $M 1$, observou-se que houve um aumento de temperatura estatisticamente significativo $(p<0,05)$ logo após a simulação da prova (M1), no qual a musculatura SM apresentou maiores aumentos na temperatura, sendo assim acredita-se que esse incremento esteja relacionado simplesmente ao esforço físico realizado, e que a musculatura mais utilizada durante a prova de três tambores seja o semimembranoso, seguido do aumento nas temperaturas dos músculos ST e GS.

Outra comparação foi realizada entre os momentos $M 0$ e $M 2$, revelando o quão próximo da temperatura basal está aquela obtida em cada musculatura duas horas após o exercício, tendo em vista que o exercício aumenta a produção de calor corporal e que termorregulação através de ajustes do fluxo 

equinos da modalidade esportiva de três tambores. PUBVET, Londrina, V. 6, N. 29, Ed. 216, Art. 1437, 2012.

sanguíneo é eficiente para manter a estabilidade térmica (MCCUTCHEON; GEOR, 2008). Observou-se que não houve diferença estatisticamente significativa $(p>0,05)$ entre a temperatura antes e 2 horas após o percurso realizado, e que as musculaturas ST e SM chegaram muito próximas às obtidas inicialmente. Em relação a musculatura, o GS permaneceu com elevação de mais de $1^{\circ} \mathrm{C}$ no $\mathrm{M} 2$ em relação ao $\mathrm{M} 0$, sugerindo-se ser esta musculatura a de menor condicionamento, possivelmente pela maior dificuldade de exercícios localizados nessa região. No entanto, esta alteração não pode ser considerada como uma alteração efetiva, já que segundo Costa et al. (2009) a musculatura que foi forçada ao extremo necessita de 24 horas para retornar completamente a sua temperatura basal. Nesse mesmo estudo também foi constatado que a temperatura da pele sobre o músculo glúteo é a que precisou de maior tempo para voltar ao normal.

Turner et al. (2001), avaliaram termograficamente 95 cavalos de corrida, e constataram que lesões musculares também podiam ser diagnosticadas até 2 semanas antes de manifestarem sinais clínicos. Segundo Resende (2005), a raça Quarto-de-Milha, em suas diversas modalidades esportivas apresenta muitos casos envolvendo lesões nos músculos semitendinoso e semimembranoso. Pela sensibilidade desse método, demonstrou-se que a termografia inclui-se em um bom método de diagnóstico precoce de lesões nessa área, favorecendo assim o prognóstico das mesmas. Segundo Mikail (2010), a termografia chega a ser até 20 vezes mais sensível do que a palpação na deteç̧ão do calor, pois acusa variações de temperatura a partir de $0,05^{\circ} \mathrm{C}$. Sendo assim, a visualização dos padrões colorimétricos associada a variação de temperatura demonstraram que o exame termográfico é uma ferramenta para a detecção de possíveis lesões musculares e condicionamento muscular, interferindo na participação do equino em uma prova de três tambores. 


\section{CONCLUSÕES}

A termografia dos músculos testados demonstrou ser uma técnica nãoinvasiva e de fácil execução, sensível às alterações de temperatura nos 3 grupos musculares testados dos cavalos praticantes da modalidade equestre de três tambores. Possibilitou também verificar o condicionamento dessas musculaturas, devido principalmente á ausência de diferença estatisticamente significante entre os lados, além do retorno à temperatura de repouso após 2 horas, fator importante para um animal de esporte principalmente na prevenção de lesões dos músculos que são exigidos durante uma prova como a de três tambores.

O estudo termográfico também demonstra grande importância para treinadores e cavaleiros, uma vez que, nos resultados individuais dos animais não foi constatada nenhuma alteração patológica, com balanceamento entre as musculaturas direita e esquerda, que acaba refletindo no seu desempenho atlético. Entre as musculaturas pesquisadas foi possível notar que o músculo semimembranoso foi o mais exigido, assim como provavelmente o músculo glúteo superficial, apesar de ser uma musculatura extensa, obteve menor condicionamento nos referidos animais, e que durante a prova de três tambores foi exigido de forma bem similar ao músculo semitendinoso.

A análise termográfica demonstrou ser útil na avaliação do status fisiológico da musculatura da região da garupa, que é muito requerida na prova de três tambores, possibilitando prever o diagnóstico de um possível quadro de lesão muscular e um instrumento de auxílio no treinamento dos animais da medicina esportiva equestre.

COMITÊ De ÉtICA e BIOSSEguRANÇA: Aprovação no Comitê de Ética em pesquisa e experimentação animal (CEPan) sob o $n^{\circ}$ de protocolo 179/2012. 


\section{REFERÊNCIAS}

BASILE, R.C. et al. Guia prático de exames termográficos em equinos. Revista Brasileira de Medicina Equina, v.6, n.31, p.24-28, 2010.

BOFFI, M.F. et al. Patologías que afectan el rendimento desportivo. In: BOFFI, M.F. Fisiologia Del Ejercicio em Equinos. Buenos Aires: Inter-Médica, 2006. Cap.18, p. 255-289.

COSTA, A.P.D. et al. Thermography in the Evaluation of Hind Limb Muscles in Horses after a Cross Country Test. Proceedings of the $\mathbf{1 1}^{\text {th }}$ International Congress of the World Equine Veterinary Association, 2009.

JODKOWSKA, E. et al. The Maximum Temperatures Distribution on the Body Surface of Sport Horses. Journal of Life Sciences, v. 5, p. 291-297, 2011. Disponível em http://bib.irb.hr/datoteka/549325.JLS-2011-4 2.pdf. Acesso em 07 de fevereiro 2011.

MCCUTCHEON, L.J.; GEOR, R.J. Thermoregulation and exercise-associated heat stress. In: HINCHCLIFF, K.W.; GEOR, R.J.; KANEPS, A.J. Equine exercise physiology: the science of exercise in the athletic horse. Philadelphia: Elsevier, 2008, p.382-386.

MIKAIL, S. Aprimorando o diagnóstico. Revista Horse, p 46-47, 2010.

MITCHELL, R.D. Performing and Reporting Purchase Examinations in Performance Horses. Proceedings of the $11^{\text {th }}$ International Congress of the World Equine Veterinary Association, 2009.

RESENDE, A. M. Miosite no Cavalo Atleta. In: II SIMPÓSIO INTERNACIONAL Do CAVALO ATLETA. Belo Horizonte p. 56 - 75, 2005.

SHAMAA, A.A.; GOHAR H. M. Clinical assessment of thermography as a diagnostic and prognostic tool in horse practice. Inframation, 2002. Disponível em: http://www.armcoinspections.com/irequine/DOC FLIRcasepdf.pdf. Acessado em 13 outubro 2011.

TEODORA, C.O. et al. Research about evaluation of locomotory system of spot equine through digital infrared thermography. Bulletin USAMAV-CN, v. 64, p. 386-391, 2007. Disponível em http://journals.usamvcj.ro/veterinary/article/viewFile/2440/2281. Acessado em 07 de fevereiro de 2012.

TURNER, T.A. et al. Thermographic Assessment of Racing Thoughbreds. Proceedings of the Annual Convention of the AAEP, 2001. v. 47, p. 344-346, 2001. http://www.ivis.org/proceedings/aaep/2001/91010100344.pdf. Acesso em 07 de fevereiro de 2012.

YANMAZ, L.E.; OKUMUS, Z.; DOGAN, E. Instrumentation of Thermography and its Application in Horses. Journal Of Animal And Veterinary Advances, v. 7, n. 6, p. 858-862, 2007. Disponível em http://docsdrive.com/pdfs/medwelljournals/javaa/2007/858-862.pdf. Acesso em 07 de fevereiro de 2012. 